\title{
Spectroscopical and Electrochemical Characterisation of a (3-Mercaptopropyl)trimethoxysilane - Based Protective Coating on Aluminium Alloy 2024
}

\author{
Mohor Mihelčič, ${ }^{1}$ Angelja K. Surca, ${ }^{1}$ Ahmed Kreta, ${ }^{1}$ Miran Gaberšček ${ }^{1,2, *}$
}

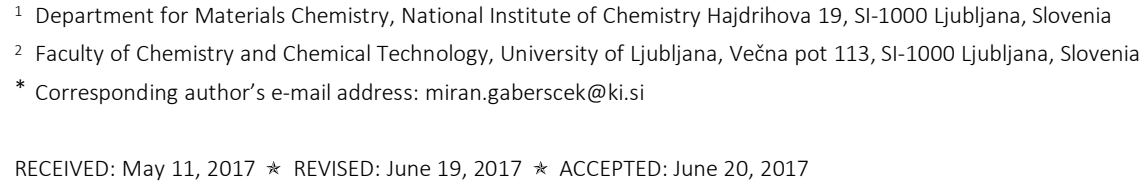

\begin{abstract}
Coatings based on organic-inorganic hybrids may effectively improve the resistance of metals/alloys against corrosion. In this work the protection ability of a coating based on (3-mercaptopropyl)trimethoxysilane (MPTMS) deposited on the well-known aluminium AA 2024 alloy is studied. The hydrolysis and condensation reactions in the initial sol and the structure of thermally treated protective MPTMS coatings is studied using infrared absorbance spectroscopy. In addition, the structure of coatings is investigated using infrared reflection-absorption (IR RA) spectroscopy. Several physical properties of prepared coatings such as contact angles, surface energy and thickness are reported. The corrosion protection ability of once, twice and three times deposited MPTMS coatings is studied using potentiodynamic polarisation measurements. Finally, possible morphological changes at different potentials of interest are investigated using in situ electrochemical AFM.
\end{abstract}

Keywords: Corrosion protection, sol-gel coatings, AA 2024, infrared spectroscopy, in situ electrochemical AFM.

\section{INTRODUCTION}

A $\mathrm{N}$ effective way to enhance the resistance of metals / alloys against corrosion is preparation of suitable protective coatings. Among others, a promising approach has been the development of organic-inorganic hybrids. [1,2] Most commonly, the approach is based on application of trialkoxysilanes $\left(\mathrm{RSi}\left(\mathrm{OCH}_{3}\right)_{3}, \mathrm{RSi}\left(\mathrm{OCH}_{2} \mathrm{CH}_{3}\right)_{3}, \ldots\right)$, having a purpose-designed organic functional group in the structure. A desired property for protective coatings is hydrophobicity, which can significantly delay the introduction of water and ionising species into the coating and consequently, in the proximity of the interface between alloy and protective coating. The hydrophobic nature is mostly determined by the functional $\mathrm{R}$ groups used. Additionally, it is possible to tailor the properties of organic-inorganic coatings to serve as surface coupling agents to enhance the bonding between the metal / alloy and the upper laying paint protection, i.e. as primer layers. ${ }^{[3]}$
A well known species that can effectively chemisorb on a metal surface is the mercapto group. For this reason, protective coatings based on a (3-mercaptopropyl)trimethoxysilane precursor comprising a mercapto $\mathrm{S}-\mathrm{H}$ group in its structure (Figure 1) have been proposed. The formation of self-assembled layers on various metals ${ }^{[4]}$ is a consequence of the ability of the thiol tail to form a covalent bond to metals such as copper, aluminium, gold and others. The formation of protective coatings on different metals / alloys has been studied and their protective characteristics determined. ${ }^{[5-9]}$ Sulphur compounds are known inhibitors for copper, which however is also known to be the most vulnerable point of aluminium alloy AA 2024. [10] Therefore it is not surprising that bis-[3-(triethoxysi|yl)propyl]tetrasulfide has already been proposed several times for potential preparation of efficient protective coatings on AA 2024. ${ }^{[11,12]}$

A deeper insight into the characteristic structure of (3-mercaptopropyl)trimethoxysilane (MPTMS) precursor (Figure 1), potential covalent bonding on the AA 2024 alloy 
and the nature of sol-gel reactions of methoxysilyl groups $\left(-\mathrm{Si}(\mathrm{OMe})_{3}\right)$ can be gained by appropriate implementation of spectroscopic investigation. For example, conventional IR absorbance measurements can help understand the reactions of hydrolysis and condensation that start to occur already in sols. ${ }^{[6,13]}$ The insight into the structure of the coating, however, can be obtained using IR reflectionabsorption (IR RA) measurements at a near-grazing incidence angle conditions $\left(80^{\circ}\right)$. The longitudinal optical (LO) modes are obtained in IR RA spectra, usually being shifted towards the higher wavelengths compared to transversal optical (TO) modes obtained in IR absorbance spectra. ${ }^{[10,13]}$ These shifts occur due to the intrinsic dielectric properties of the materials. Consequently, the assignment of the LO modes in IR RA spectra of MPTMS protective coatings can be carried out on the basis of previously developed knowledge on trialkoxysilanes. ${ }^{[13,14-16]}$

The eventual changes in topography of the MPTMS coatings during the corrosion process can be effectively monitored using in situ electrochemical atomic force microscopy (AFM). ${ }^{[17,18]}$ AFM enables the investigation of conductive and non-conductive surfaces, which is a great advantage when studying corrosion processes. Namely, the formed passive layers or poorly conductive oxides may introduce a certain degree of isolation. ${ }^{[19]}$ Consequently, AFM has a great potential for studying corrosion events like formation of trenches around the intermetallic inclusions, deposition of precipitates, formation of oxyhydroxide / oxide layers, as well investigation of protective coatings deposited on metals / alloys. Such events have often been followed on a sample just immersed in an electrolyte, [20,21] while application of potential pulses and subsequent measurements of AFM images is much more rare. ${ }^{[10,22,23]}$ Anyhow, both types of measurements have mostly been designed for use in in situ mode. Commercial[22,23] or custom-made ${ }^{[10]}$ AFM cells can be effectively used. In any case, these initial study studies demonstrated that the approach could be usefully extended to other samples of interest.

In addition to monitoring the morphological changes of metals / alloys, in situ AFM investigation can also provide information about surface properties of various protective coatings exposed to different potential conditions. ${ }^{[13,19,24]}$ However, in prolonged in situ AFM measurements a certain drift of the laser during scanning is inherent. ${ }^{[25]}$ Among the successful attempts where this problem was overcome were in situ AFM measurements of tungsten monocarbidebased coatings ${ }^{[24]}$ and a study on the early stages of nucleation and growth of electrodeposited cerium oxide.[19]

In this paper the protection ability of a MPTMSbased coating is studied in some detail. In a sense, this is a follow up from a previous paper in which in situ electrochemical AFM study of another protective coating - based on 1,2-bis(trimethoxysilyl)ethane (BTMSE) - was carried out. ${ }^{[13]}$ That study revealed a decrease in the surface roughness during immersion of the coating at open circuit potential conditions, followed by very similar values during application of the chronocoulometric pulses. This indicated a reasonably stable structure of the coating during anodic polarisation. We assumed that MPTMS could reveal similar if not better protection properties than BTMSE.

\section{EXPERIMENTAL}

\section{Preparation of Sols and Coatings}

The protective coatings were prepared from (3-mercaptopropyl)trimethoxysilane (MPTMS, see Figure 1). First, MPTMS (1 g) was mixed in 2-propanol (10 g) for $10 \mathrm{~min}$. Afterwards, $0.275 \mathrm{~g}$ of $0.1 \mathrm{~mol} \mathrm{dm}^{-3}$ nitric acid was added serving as a catalyst for sol-gel reactions of hydrolysis and condensation. The sol was stirred for $3 \mathrm{~h}$ prior to the deposition of coatings via the dip-coating technique on aluminium alloy AA 2024 (Aviometal, Italy) with the following average composition (in wt. \%): > 93.6 Al, $4.24 \mathrm{Cu}, 1.33 \mathrm{Mg}$, $0.43 \mathrm{Mn}, 0.11 \mathrm{Fe}, 0.09 \mathrm{Zn},<0.2$ other. The pulling velocity was $10 \mathrm{~cm} \mathrm{~min}-1$. After deposition of the final layer, the coatings were thermally treated at $120^{\circ} \mathrm{C}$ for $2 \mathrm{~h}$. For potentiodynamic testing, coatings with three different thicknesses, i.e. 110, 280 and $500 \mathrm{~nm}$, were prepared by using 1,2 and 3 dip-coating depositions, respectively. Between various dippings, the coating was dried $15 \mathrm{~min}$ in air. Spectroscopic and in situ electrochemical AFM measurements were performed on one deposited layer of MPTMS coating - which allowed a clearer distinction of feature than in the case of thicker coatings.

Prior to deposition, AA 2024 substrates were cut into dimensions of $2 \times 5 \mathrm{~cm}^{2}$. The substrates were polished using a $3 \mathrm{M}$ Perfect-IT III polish paste and then sonificated for $15 \mathrm{~min}$ in hexane, acetone, methanol and distilled water.

\section{Instrumental}

Infrared (IR) measurements were performed on a Bruker IFS 66/S spectrometer. For IR absorbance measurements, the sols were deposited on a double side polished silicon wafers. These IR measurements were used to follow the hydrolysis and condensation reactions in the sol and also to

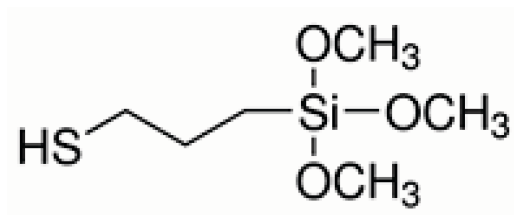

Figure 1. Structure of (3-mercaptopropyl) trimethoxysilane (MPTMS). 
investigate the structure of thermally treated protective coating. In addition, the structure of coatings was investigated using infrared reflection-absorption (IR RA) spectroscopy. For this purpose, the coatings were deposited on a reflective AA 2024 substrate and it had to be ensured that P-polarised IR radiation hit the surface of the coating at near-grazing incidence angle (NGIA) conditions.

Contact angle measurements were used for determination of surface energy values using the van Oss method. ${ }^{[26]}$ For this purpose, measurements with three liquids with known $\sigma^{\text {tot }}, \sigma^{\mathrm{LW}}, \sigma^{+}$and $\sigma^{-}$were carried out and the surface energy calculated using the prescribed protocol.

Thicknesses were measured using a Taylor Hobson Series II profilometer. The upper edge of the coating that formed during the dip-coating deposition was used for determination of the thickness. Three measurements were made: one in the center of the sample and the other two between the center and the both sides. All three measurements were averaged to obtain the thickness of the coating.

Potentiodynamic polarisation measurements were made on an Autolab PGSTAT 302N potentiostatgalvanostat in a standard K0235 flat cell (Princeton Applied Research) for corrosion measurements. The cell was filled with $250 \mathrm{ml}$ of $0.5 \mathrm{~mol} \mathrm{dm}^{-3} \mathrm{NaCl}$ electrolyte. The protective coating on AA 2024 was mounted as a working electrode. A Pt grid and an $\mathrm{Ag} / \mathrm{AgCl} / \mathrm{KCl}_{\text {sat }}$ electrode were used as a counter and a reference electrode, respectively. The protective coatings were first held at open circuit potential (OCP) for $30 \mathrm{~min}$, then the potential was swept from -1.0 to $0 \mathrm{~V}$ using linear sweep voltammetry at a scan rate of $1 \mathrm{mV} \mathrm{s}^{-1}$.

AFM imaging was performed on an Agilent 5500 device. Commercial four-sided silicon tips with a radius below $50 \mathrm{~nm}$ (producer: Nanosensors) and gold coated on the detector and tip side were used. The resonance frequency was $75 \mathrm{kHz}$ and the nominal spring constant $0.1 \mathrm{~N} \mathrm{~m}^{-1}$. The cantilever was $200 \mu \mathrm{m}$ long. The in situ electrochemical AFM images were recorded in a custommade Teflon cell having thin-layer-electrolyte configuration and three-electrode geometry. ${ }^{[10,13]}$ The investigated sample was positioned as a working electrode in the middle of the Teflon bottom as a disk having a diameter of $7 \mathrm{~mm}$ and wired from the backside. The $\mathrm{Ag} / \mathrm{AgCl} / 0.3 \mathrm{M} \mathrm{NaCl}$ reference electrode (BASi) was positioned beside the sample, as well the Pt grid counter electrode. The edges of the sample were protected by the paraffin. The opening of the cell was $43 \mathrm{~mm}$, which enabled an easy access of the scanner with the cantilever to the sample. The in situ AFM images were recorded in a tapping mode, so that the repositioning or the corrosion reatures could be avoided. The scanning rate was $2 \mathrm{~Hz}$ and the dimensions of images $10 \times 10 \mu \mathrm{m}^{2}$. The cell was filled with approximately $5 \mathrm{~mL}$ of $0.5 \mathrm{~mol} \mathrm{dm}^{-3} \mathrm{NaCl}$ electrolyte. The images were detected at open circuit potential (OCP) and after application of chronocoulometric pulses at $-0.8,-0.6$ and $-0.4 \mathrm{~V}$ vs. $\mathrm{Ag} / \mathrm{AgCl} / 0.3 \mathrm{M} \mathrm{NaCl}$. The duration of chronocoulometric pulses was $20 \mathrm{~s}$ at each potential and then the AFM image was collected. Time in min referes to time of immersion of the sample in the electrolyte. Several images after each application of the potential pulse were recorded.

\section{RESULTS}

\section{IR Spectroscopic Characteristics of MPTMS Sols and Coatings}

By monitoring the hydrolysis and condensation reactions in sols, one may gain information on initiation of the structural evolution of the coating. Time-dependent IR absorbance spectroscopy is a suitable analytical technique for this purpose. At certain time intervals after the addition of the sol-gel catalyst ( 1 and $30 \mathrm{~min} ; 1,4,24 \mathrm{~h}$ ), the sol is deposited on a silicon wafer, transferred into the sample compartment of the IR spectrometer and IR absorbance spectra measured (Figure 2). For comparison, IR spectrum of the trialkoxysilane precursor MPTMS is shown in Figure $2 \mathrm{~A}$ in order to give evidence on the presence of mercapto band at $2567 \mathrm{~cm}^{-1}$.

In addition to mercapto group, the most important characteristic in the MPTMS spectrum are the bands of methoxy groups, i.e. asymmetric $v_{a}\left(\mathrm{Si}-\mathrm{OCH}_{3}\right)$ and symmetric $v_{s}\left(\mathrm{Si}_{-}-\mathrm{OCH}_{3}\right)$ stretching at 2943 and $2840 \mathrm{~cm}^{-1}$, and the other modes of this group appearing at 1192, 1086 and $812 \mathrm{~cm}^{-1}$ (Figure 2). These modes decreased in intensity in the spectrum obtained 1 min after the addition

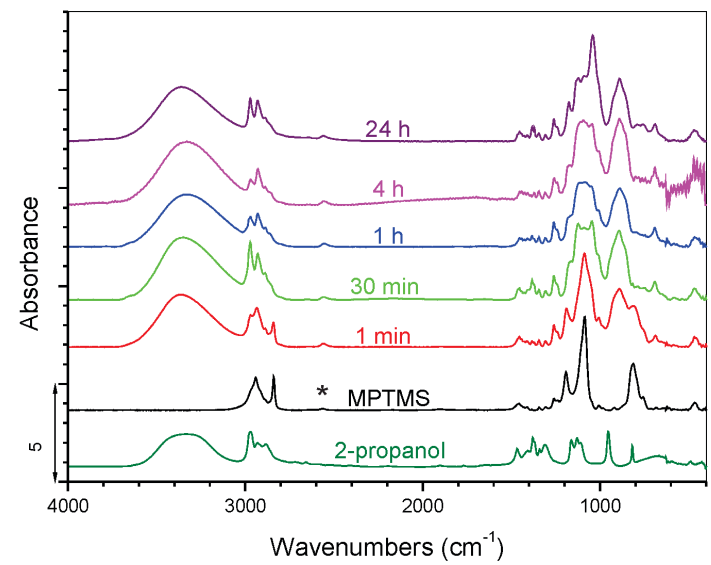

Figure 2. Time-dependent IR absorbance spectra of MPTMSbased sol after addition of a $0.1 \mathrm{M} \mathrm{HNO}_{3}$ sol-gel catalyst. The precursor and sol were deposited on a silicon wafer. For clarity, the position of mercapto group band at $2560 \mathrm{~cm}^{-1}$ is denoted by asterisk $\left(^{*}\right)$ in the spectrum for MPTMS precursor. 
of $0.1 \mathrm{M} \mathrm{HNO}_{3}$, and disappeared from the spectrum recorded after $30 \mathrm{~min}$. This indicated that the methoxy groups were no more present in sols and that their hydrolysis occurred.

The next evidence that the hydrolysis took place was the appearance of a broad silanol $v(\mathrm{Si}-\mathrm{OH})$ band around $900 \mathrm{~cm}^{-1}$ in the spectrum obtained after $1 \mathrm{~min}$. In accordance with the decrease in the intensity of the methoxy bands, the intensity of the silanol band increased in the spectrum collected after $30 \mathrm{~min}$. Nevertheless, the broad band at around $3350 \mathrm{~cm}^{-1}$ and other low-intensity bands in the low frequency region showed that 2-propanol solvent was still present in the sample. These changes are consistent with those described by Chen et al., ${ }^{[6]}$ but much faster. The reason may be the strength of the sol-gel catalyst used, i.e. $\mathrm{HNO}_{3}$ in our sol vs. acetic acid used by Chen et al. ${ }^{[6]}$ The mercapto group band appeared at $2560 \mathrm{~cm}^{-1}$ in the spectrum of the MPTMS precursor (Figure 2) and remained visible also in the spectra of hydrolysed sol (1 $\mathrm{min}$ to $24 \mathrm{~h}$ ), i.e. obviously no covalent bonding to the silicon wafer used as a substrate for IR absorbance measurements took place.

The features in the region of siloxane modes (1200$1000 \mathrm{~cm}^{-1}$ ) changed significantly during $24 \mathrm{~h}$ of IR absorbance measurements (Figure 2). The initially existing modes of methoxysilyl groups gradually changed into a broad overlapped band compilation ( 30 min to $4 \mathrm{~h}$ ), finally reflecting a strong and distinct band at $1041 \mathrm{~cm}^{-1}$ with shoulder bands at 1088 and $1122 \mathrm{~cm}^{-1}$. Similar features were noted also by Chen et al. ${ }^{[6]}$ who proposed that Si-O-Si band at higher frequency could be attributed to cyclic siloxane units, while the one at lower frequency is due to long Si-O-Si chains. It may further be noted that in IR spectra of polyhedral oligomeric silsesquioxanes (POSS) various POSS are characterised by a sharp band in the region of 1115$1125 \mathrm{~cm}^{-1}\left(v_{\mathrm{a}}(\mathrm{Si}-\mathrm{O}-\mathrm{Si})\right)$ and symmetric $v_{\mathrm{s}}(\mathrm{Si}-\mathrm{O}-\mathrm{Si})$ stretching around $480 \mathrm{~cm}^{-1}$.[27] POSS are characterised by a cube-like regular structure $\left(\left(\mathrm{R}-\mathrm{SiO}_{3 / 2}\right)_{n}(n=6,8,10,12, \ldots)\right.$. From the behaviour of band at $1041 \mathrm{~cm}^{-1}$ it may be concluded that with increasing time longer $\mathrm{Si}-\mathrm{O}-\mathrm{Si}$ chains were formed in MPTMS sols (Figure 2). On the other hand, the appearance of the bands at $1122 \mathrm{~cm}^{-1}$ and the slight increase in the intensity of $468 \mathrm{~cm}^{-1}$ band indicated the formation of cyclic

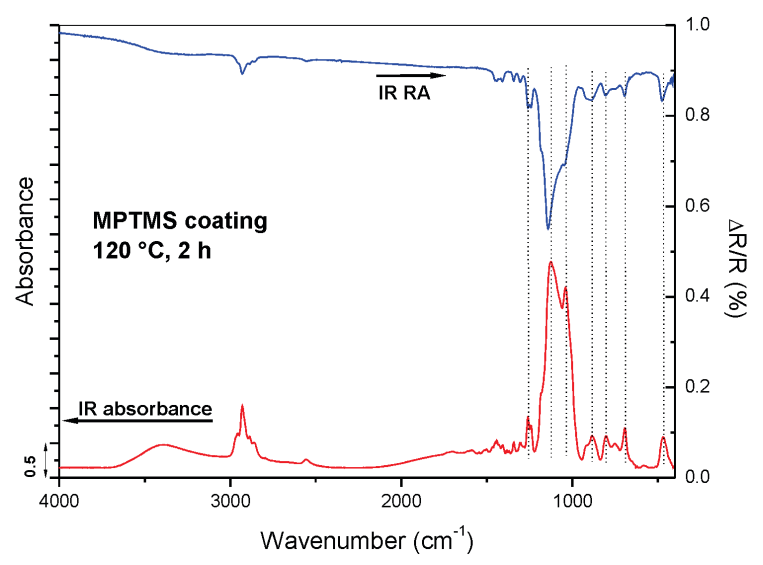

Figure 3. IR absorbance (red) and IR RA (blue) spectra of MPTMS coatings thermally treated at $120^{\circ} \mathrm{C}$ for $2 \mathrm{~h}$.

siloxane units and followed by formation of silsesquioxane matrix to some extent. Consequently, the time chosen for the deposition of the coatings can significantly influence their structure and also their protective efficiency.

The structure of MPTMS coatings detected on silicon wafer using IR absorbance spectroscopy and on AA 2024 by IR RA spectroscopy are depicted in Figure 3. During thermal treatment, the siloxane region within the IR absorbance spectrum changed considerably. The band at $1041 \mathrm{~cm}^{-1}$ significantly decreased in intensity and appeared as a shoulder band, while the bands at 1126 and $469 \mathrm{~cm}^{-1}$ increased in intensity.

These changes showed that silsesquioxane matrix continuously formed. On the other hand, the spectrum still showed some extent of the solvent present (broad band around $3400 \mathrm{~cm}^{-1}$ ) and the silanol bonds at $912 \mathrm{~cm}^{-1}$. This revealed that not all $\mathrm{Si}-\mathrm{OH}$ groups contributed to the condensation reactions and some of them still remained unreacted. Consequently, the coating is not completely crosslinked. The same conclusions can be drawn from IR RA spectrum of MPTMS coating deposited on AA 2024 alloy. As expected, the development of IR absorbance spectra confirmed that the largest changes occurred in the siloxane region.

The presence of coating, i.e. MPTMS/AA 2024, decreased the contact angle for water in comparison to the

Table 1. Contact angles and surface energy values of MPTMS coating and AA 2024 alloy substrate.

\begin{tabular}{|c|c|c|c|c|c|c|c|c|}
\hline \multirow{2}{*}{ Coating } & \multicolumn{3}{|c|}{$\Theta /^{\circ}$} & \multirow{2}{*}{$\tau^{+}$} & \multirow{2}{*}{$\tau^{-}$} & \multirow{2}{*}{$\tau^{\mathrm{LW}}$} & \multirow{2}{*}{$\tau^{\mathrm{AB}}$} & \multirow{2}{*}{$\tau^{\text {tot }}$} \\
\hline & $\mathrm{H}_{2} \mathrm{O}$ & $\mathrm{CH}_{2} \mathrm{I}_{2}$ & $\mathrm{HCONH}_{2}$ & & & & & \\
\hline AA 2024 & 86.0 & 47.7 & 61.7 & 0.2 & 3.0 & 35.6 & 1.6 & 37.1 \\
\hline MPTMS/AA 2024 & 65.4 & 44.9 & 39.7 & 1.9 & 2.7 & 30.4 & 10.4 & 40.8 \\
\hline
\end{tabular}


value for unprotected aluminium alloy AA 2024 (Table 1). The value of $65.4^{\circ}$ obtained for the MPTMS/AA 2024 sample heat treated at $120{ }^{\circ} \mathrm{C}$ reflected an incompletely condensed sol-gel structure. Unreacted silanol groups were still present in the coating - consistent with its more hydrophilic character. Accordingly, the surface energy value was also somewhat higher for the coating $\left(40.8 \mathrm{~mJ} \mathrm{~m}^{-2}\right)$ than for bare AA 2024 alloy $\left(37.1 \mathrm{~mJ} \mathrm{~m}^{-2}\right)$. These values, however, were still much higher than those obtained for protective coatings that additionally contained poly(dimethylsiloxane) (PDMS) chains. Namely, $\sigma^{\text {tot }}$ of such PDMS-based coatings achieved values even below $22.6 \mathrm{~mJ} \mathrm{~m}^{-2}$.[14-16]

\section{Electrochemical Characterisation}

The potentiodynamic curves were examined for once, twice and triple deposited MPTMS coatings and compared with the response of unprotected aluminium alloy AA 2024 (Figure 4). Obviously, the presence of coatings decreased significantly both the cathodic and anodic current densities. More specifically, in the case of once deposited MPTMS coating the cathodic current decreased for about 1 to 1.5 orders of magnitude whereas in the anodic branch the decrease was about one order of magnitude. Although this decrease might not seem very impressive, we note that the average coating thickness was merely about $110 \mathrm{~nm}$.

As shown later on, such a layer still contains some indentations and other defects contributing to the surface inhomogeneity. Interestingly, in twice and three times coated samples the coating thickness increased faster than linearly and achieved average values of 280 and $500 \mathrm{~nm}$, respectively. Probably, the previously deposited layer(s) served as a good anchor for deposition of the next layer. Despite the important difference in thickness, however, the protective nature of the $280 \mathrm{~nm}$ and $500 \mathrm{~nm}$ - thick

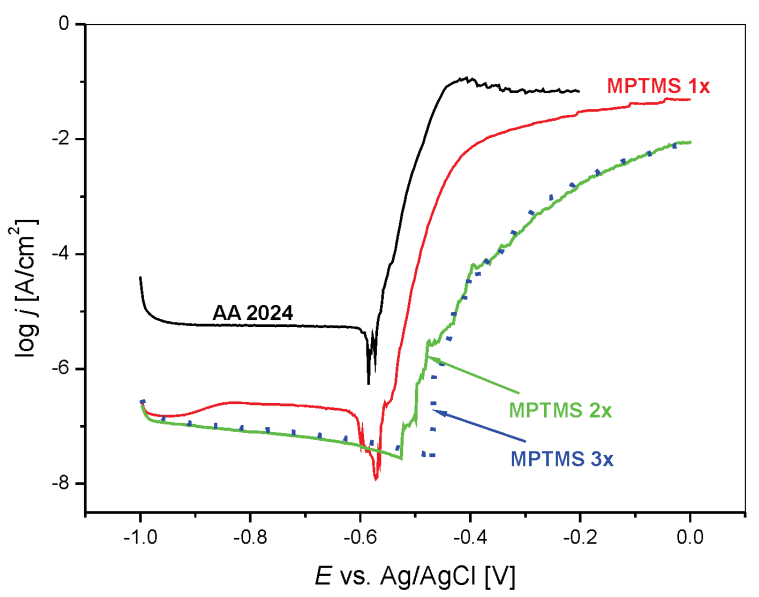

Figure 4. Potentiodynamic polarisation measurements of MPTMS coatings with different thicknesses as determined using profilometry (see Instrumental). coatings was quite comparable: in both cases the decrease in the cathodic current density was about two orders of magnitude, whereas in the anodic direction it reached about 3-4 orders of magnitude. Thus, there is a very significant improvement between the first and the second coating while further coating does not seem to further increase the protection. Apparently, two layers are sufficient to cover the surface completely (crack, defects etc. that remain upon first coating are sealed completely by the next layer). Thus the properties of twice / three times deposited coating probably already reflect the ultimate protection ability of MPTMS determined by the nature of pores and other small scale defects in intrinsic MPTMS.

\section{In situ Electrochemical AFM}

In situ electrochemical AFM was used to probe the behaviour of MPTMS coatings under the anodic conditions. In particular, we were interested in their mechanical durability / stability which could be correlated to their resistance to morphological changes. We estimated that the effects would be best visible in the thinnest coating prepared - the once deposited with a thickness around $110 \mathrm{~nm}$.

AFM images were first recorded at OCP conditions (Figure 5a). In the next step, the coated sample was chronocoulometrically charged at -0.8 and $-0.4 \mathrm{~V}$ for $20 \mathrm{~s}$, i.e. more negative and positive than the corrosion potential (Figure 5). After each potential pulse, three to four AFM images were taken and the representative ones shown in Figure $5(b, c)$. During the whole procedure the coating was immersed in a $0.5 \mathrm{~mol} \mathrm{dm}^{-3} \mathrm{NaCl}$ electrolyte. Changes in the coating can result both from the immersion into the saltcontaining electrolyte and, additionally, due to application of the potential pulse. Based on our experience, however, changes resulting from immersion only are mainly expected in the case of unprotected metals or alloys. In the case of coatings such changes are much less significant but can sometimes be enhanced under anodic polarisation.

The image obtained at OCP (Figure 5A) revealed a relatively homogeneous topography of the MPTMS protective coating although some small indentations can be observed. The rms value obtained was $0.65 \mathrm{~nm}$. When a potential lower than the corrosion potential was applied, i.e. $-0.8 \mathrm{~V}$, the appearance of the AFM image did not change (Figure 5B). However, according to the measured features in Figure 5 it can be concluded that the position of the images slightly shifted. This effect is a consequence of thermal drift, which is impossible to be avoided during long-lasting AFM experiments. ${ }^{[10,13,25]}$

At anodic potentials the main characteristic features of the images remained more or less intact, including at the harshest conditions used - the anodic potential of $-0.4 \mathrm{~V}$ (Figure 5C). A closer examination, however, showed a slight relaxation of the coating and the linking of the indentations, 


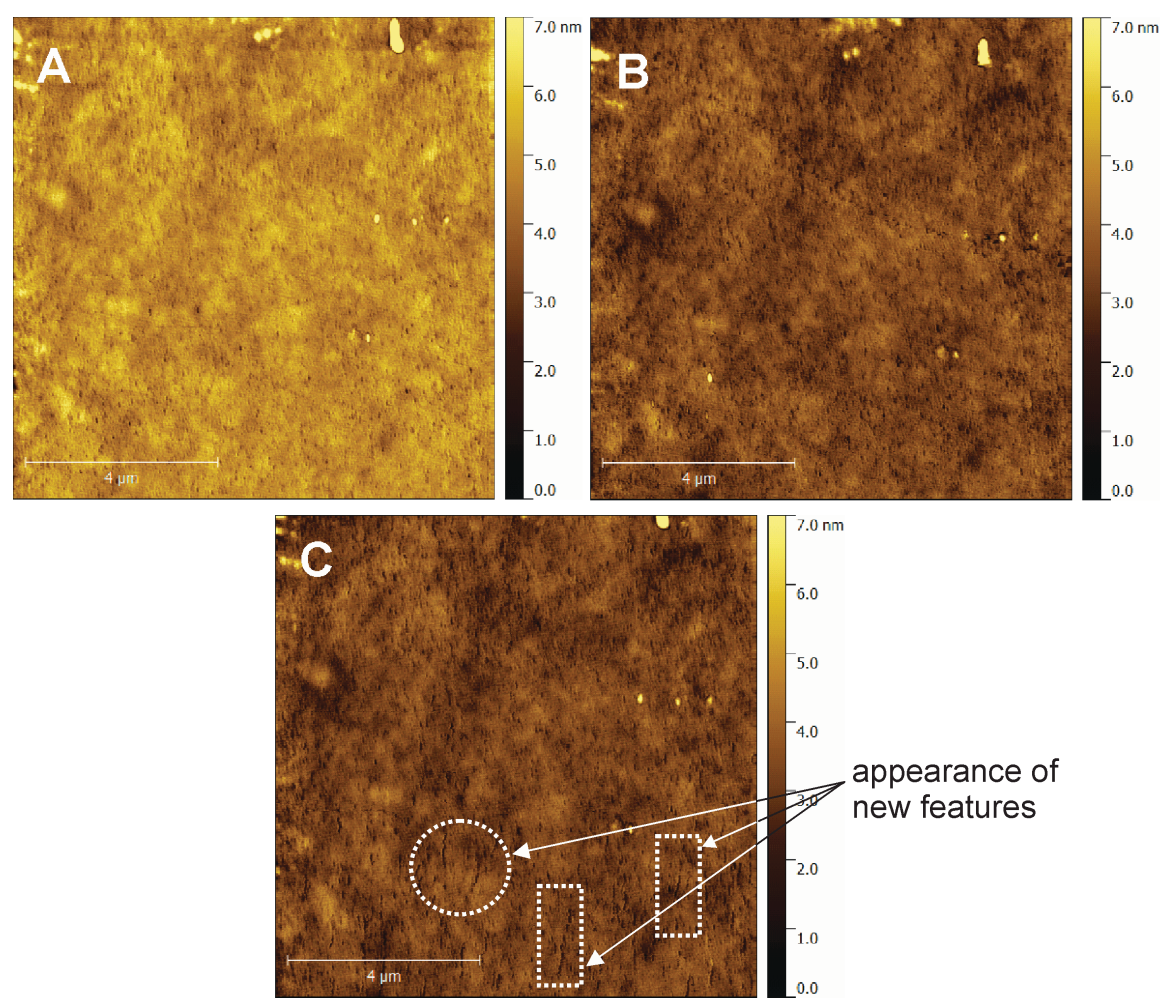

Figure 1. In situ AFM images of the MPTMS coating deposited on AA 2024 alloy: A) OCP, 44 min; rms $=0.65 \mathrm{~nm}$; B) $-0.8 \mathrm{~V}$, $73 \mathrm{~min} ; \mathrm{rms}=0.69 \mathrm{~nm} ; \mathrm{C})-0.4 \mathrm{~V}, 108 \mathrm{~min} ; \mathrm{rms}=0.67 \mathrm{~nm}$. The potential pulse duration was $20 \mathrm{~s}$ in each case. The time in min is the time after immersion of the sample in $0.5 \mathrm{M} \mathrm{NaCl}$ electrolyte.

especially at most anodic potentials. The loosening of the coating structure could be a consequence of the formation of aluminium oxide / oxyhydroxides at the interface between the AA 2024 alloy and the deposited MPTMS coating. This is also reflected in the slightly increased $\mathrm{rms}$ factor, i.e. from $0.65 \mathrm{~nm}$ to $0.67-0.69 \mathrm{~nm}$. These findings are in complete accordance with our previous study on BTMSE protective coatings on AA 2024. ${ }^{[13]}$ The thickness of BTMSE coatings was comparable with the thickness of MPTMS coatings, i.e. $120 \mathrm{~nm}$ (BTMSE) vs. $110 \mathrm{~nm}$ (MPTMS).

\section{CONCLUSIONS}

Formation of protective coatings based on (3-mercaptopropyl) trimethoxysilane (MPTMS) deposited on AA 2024 alloy was studied in detail. The methoxy groups gradually decreased and completely disappeared after about 30 minutes signifying that the hydrolysis process was successfully completed. With increasing time longer $\mathrm{Si}-\mathrm{O}-\mathrm{Si}$ chains were formed in MPTMS sols. Formation of cyclic siloxane units and occurrence of silsesquioxane matrix was also successfully observed. The results show that the time chosen for the deposition of the coatings can significantly influence their structure and also their protective efficiency. As regards the condensation step, we found that not all $\mathrm{Si}-\mathrm{OH}$ groups contributed to the condensation reactions, i.e. some of them still remained unreacted. Consequently, the coating was not completely crosslinked.

The thicknesses of once, twice and triple deposited MPTMS coatings were 110, 280 and $500 \mathrm{~nm}$, respectively. Two layers sufficed for a maximum corrosion protection of developed MPTMS coatings, that is, for a decreasee of the anodic currents by about 3-4 orders of magnitude with respect to uncoated AA 2024 alloy. According to in-situ AFM study, the coatings are robust and no significant changes upon exposure to $0.5 \mathrm{~mol} \mathrm{dm}^{-3} \mathrm{NaCl}$ electrolyte under cathodic or anodic conditions could be detected.

Acknowledgment. The research leading to these results has received a funding from the project L2-5484 and the Programme P2-0393 of the Slovenian Research Agency (ARRS). Ahmed Kreta acknowledges ARRS for his Ph.D. funding.

\section{REFERENCES}

[1] D. Wang, G. P. Bierwagen, Prog. Org. Coat. 2009, 64, 327.

[2] W.J. van Ooij, D. Zhu, M. Stacy, A. Seth, T. Mugada, J. Gandhi, P. Puomi, Tsinghua Sci. and Technol. 2005, 10, 639. 
[3] F. Deflorian, S. Rossi, L. Fedrizzi, Electrochim. Acta 2006, 51, 6097.

[4] S. Hosseinpour, M. Forslund, C. M. Johnson, J. Pan, C. Leygraf, Surf. Sci. 2016, 648, 170.

[5] F. Zucchi, A. Frignani, V. Grassi, G. Trabanelli, M. DalColle, Corros. Sci. 2007, 49, 1570.

[6] M.-A. Chen, X.-B. Lu, Z.-H. Fuo, R. Huang, Corros. Sci. 2011, 53, 2793.

[7] S. Peng, Z. Zeng, W. Zhao, J. Chen, J. Han, X. Wu, Surf. Coat. Technol. 2014, 251, 135.

[8] Y.-S. Li, Y. Wang, T. Tran, A. Perkins, Spectrochim. Acta A 2005, 61, 3032.

[9] Y.-S. Li, W. Lu, Y. Wang, T. Tran, Spectrochim. Acta A 2009, 73, 922.

[10] A. Kreta, M. Rodošek, L. Slemenik Perše, B. Orel, M. Gaberšček, A. Šurca Vuk, Corros. Sci. 2016, 104, 290.

[11] D. Zhu, W. J. van Ooij, Corros. Sci. 2003, 45, 2177.

[12] A. Cabral, R.G. Duarte, M. F. Montemor, M. L. Zheludkevich, M. G. S. Ferreira, Corros. Sci. 2005, 47, 869.

[13] M. Rodošek, A. Kreta, M. Gaberšček, A. Šurca Vuk, Corros. Sci. 2016, 102, 186.

[14] M. Fir, B. Orel, A. Šurca Vuk, A. Vilčnik, R. Ješe, V. Francetič, Langmuir 2007, 23, 5505.

[15] A. Rauter, L. Slemenik Perše, B. Orel, B. Bengű, O.
Sunetci, A. Šurca Vuk, J. Electroanal. Chem. 2013, 703, 97.

[16] M. Rodošek, A. Rauter, L. Slemenik Perše, D. Merl Kek, A. Šurca Vuk, Corros. Sci. 2014, 85, 193.

[17] N. Jalili, K. Laxminarayana, Mechatronics 2004, 14, 907.

[18] F.J. Giessibl, Rev. Mod. Phys. 2003, 75, 949-.

[19] F. B. Li, R. C. Newman, G. E. Thompson, Electrochim. Acta 1997, 42, 2455.

[20] K. Kowal, J. DeLuccia, J.Y. Josefowicz, C. Laird, G. C. Farrington, J. Electrochem. Soc. 1996, 143, 2471.

[21] (a) L. Roué, L. Chen, D. Guay, Langmuir 1996, 12, 5818; (b) P. Schmutz, G.S. Frankel, J. Electrochem. Soc. 1998, 145, 2295.

[22] R. M. Rynders, C.-H. Paik. R. Ke, R. C. Alkire, J. Electrochem. Soc. 1994, 141, 1439.

[23] P. Leblanc, G. S. Frankel, J. Electrochem. Soc. 2002, 149, B239.

[24] J. M. Perry, A. Neville, T. Hodgkiess, J. Therm. Spray Technol. 2002, 11, 536.

[25] U. K. Mudali, N. Padhy, Corros. Rev. 2011, $29,73$.

[26] C. J. van Oss, R. J. Good, M. K. Chaudhury, Langmuir 1988, 4, 884.

[27] I. Jerman, A. K. Surca, M. Koželj, F. Švegl, B. Orel, Prog. Org. Coat. 2011, 72, 334. 